\title{
Thrombocytopenia in liver disease
}

\author{
Markus Peck-Radosavljevic MD
}

\begin{abstract}
M Peck-Radosavljevic. Thrombocytopenia in liver disease. Can J Gastroenterol 2000;14(Suppl D):60D-66D. Moderate thrombocytopenia is a frequent finding in cirrhosis of the liver and well tolerated in most instances. The pathophysiology of thrombocytopenia in liver disease has long been associated with the concept of hypersplenism, where portal hypertension was thought to cause pooling and sequestration of all corpuscular elements of the blood, predominantly thrombocytes in the enlarged spleen. The concept of hypersplenism was never proven beyond any doubt but was widely accepted for the lack of alternative explanations.

With the discovery of the lineage-specific cytokine thrombopoietin (TPO) the missing link between hepatocellular function and thrombopoiesis was found. TPO is predominantly produced by the liver and constitutively expressed by hepatocytes. TPO production in humans is dependent on functional liver cell mass and is reduced when liver cell mass is severely damaged. This leads to reduced thrombopoiesis in the bone marrow and consequently to thrombocytopenia in the peripheral blood of patients with advanced-stage liver disease.

With recombinant TPOs in development, patients with liver disease and TPO seem to be the ideal target population for this drug. Once the efficacy of thrombopoietin in patients with liver disease is proven, a potent yet safe drug may be available to treat cirrhotic patients undergoing invasive or surgical procedures, during bleeding episodes or when undergoing therapy with myelosuppressive drugs such as interferon-alpha.
\end{abstract}

Key Words: Cirrhosis; Liver disease; Liver transplantation; Thrombocytopenia; Thrombopoietin (TPO)

\section{Thrombocytopénie et maladie hépatique}

RÉSUMÉ : La thrombocytopénie modérée s'observe souvent dans la cirrhose hépatique et elle est bien tolérée dans la plupart des cas. La physiopathologie de la thrombocytopénie dans la maladie hépatique est depuis longtemps associée à la notion d'hypersplénisme, selon laquelle l'hypertension causerait l'accumulation et la séquestration de tous les éléments corpusculaires du sang, surtout des thrombocytes, dans la rate hypertrophiée. Le concept d'hypersplénisme n'a jamais été confirmé hors de tout doute, mais a largement été accepté à défaut d'autres explications.

Depuis la découverte de la thrombopoïétine liée aux cytokines thrombopoïétiques spécifiques à la lignée, on semble avoir trouvé le chaînon manquant entre la fonction hépatocellulaire et la thrombopoìèse. La TPO est avant tout produite par le foie et essentiellement exprimée par les hépatocytes. La production de TPO chez l'être humain dépend de la masse cellulaire hépatique fonctionnelle et se trouve réduite lorsque cette dernière est sérieusement compromise. Cela entraîne une réduction de la thrombopoièse dans la moelle osseuse et, par conséquent, la thrombocytopénie au niveau du sang périphérique des patients atteints de maladie hépatique avancée. Grâce aux TPO recombinantes en cours de développement, les patients souffrant de maladie hépatique et de thrombocytopénie semblent être la population cible idéale pour ce médicament. Une fois que l'efficacité de la thrombopoḯtine chez les patients atteints de maladie hépatique aura été confirmée, on disposera d'un médicament puissant et sécuritaire pour traiter les patients cirrhotiques qui doivent subir des interventions effractives ou chirurgicales, lors d'épisodes hémorragiques ou lors d'un traitement myélosuppresseur à l'interféron-alpha, par exemple.

\section{EPIDEMIOLOGY OF THROMBOCYTOPENIA IN LIVER DISEASE}

Thrombocytopenia in cirrhosis of the liver is a fairly frequently observed phenomenon, occurring in 15\% to $70 \%$ of patients with cirrhosis, depending on the stage of disease and the definition of thrombocytopenia (1). It is usually mild to moderate in severity, and its degree can be viewed as a prognostic marker (2). However, there is little evidence to date suggesting an association with the increased risk of bleeding from esophageal varices or other causes in patients with stable liver disease (3-5), unless undergoing major surgery (6). Even liver biopsy appears to be quite safe unless severe

This mini-review was prepared from a presentation made at the World Congress of Gastroenterology, Vienna, Austria, September 6 to 11, 1998 Department of Gastroenterology and Hepatology, University of Vienna Medical School, Vienna, Austria

Correspondence and reprints: Dr Markus Peck-Radosavljevic, Department of Gastroenterology and Hepatology, AKH Wien,

Währinger Gürtel 18-20, A-1090 Vienna, Austria. Telephone +43-1-40400-4741, fax +43-1-40400-4735, e-mail marcus.peck@akh-wien.ac.at Received for publication January 15, 1999. Accepted January 20, 1999 
thrombocytopenia (usually less than 50,000 platelets $/ \mu \mathrm{L}$ ) is present (7). The risk of bleeding increases only when there are signs of ongoing consumption coagulopathy in patients with decompensated cirrhosis, but peripheral platelet counts have not been shown to be a risk factor for bleeding in these patients (8).

Thrombocytopenia in liver disease can have various etiologies. Mostly, thrombocytopenia is associated with liver cirrhosis but can also be due to autoantibodies against platelets $(9,10)$, the myelosuppressive action of viral agents such as hepatitis $\mathrm{C}$ virus (HCV) $(11,12)$, the toxic effects of excessive alcohol ingestion and therapy of chronic liver disease with interferon $(13,14)$. This review will focus on the pathophysiology of thrombocytopenia associated with cirrhosis of the liver; platelet autoantibodies will not be discussed in detail.

\section{THROMBOCYTOPENIA IS LINKED TO CIRRHOSIS}

Thrombocytopenia in liver disease is always linked to cirrhosis, except in cases of HCV infection, where either autoantibodies against platelet antigens, or the $\mathrm{HCV}$ itself, can cause thrombocytopenia in noncirrhotic patients through bone marrow suppression (12).

The mechanisms leading to thrombocytopenia in cirrhosis of the liver, aside from HCV infection, are not so clear. Most commonly, thrombocytopenia has been attributed to portal hypertension and splenic pooling of platelets (15). Low-level consumption coagulopathy has been discussed in relation to cirrhosis and has been suggested as being a possible cause of thrombocytopenia, but careful coagulation studies in patients with cirrhosis do not suggest consumption coagulopathy in most patients with cirrhosis (16). Furthermore, data from elegant studies, such as those by Violi et al $(8,17)$, do not show lower platelet counts in patients with low-level disseminated intravascular coagulation compared with patients without the condition.

Recently, decreased thrombopoeitin (TPO) production in the cirrhotic liver has been show to play an important role and may be the most important factor for the majority of patients with cirrhosis and thrombocytopenia (18-20).

\section{PORTAL HYPERTENSION - THE EVIDENCE}

For many years, portal hypertension was thought to induce splenomegaly, and splenomegaly was presumed to cause thrombocytopenia through an increased pooling or destruction of platelets (15). Splenic pooling of platelets has been demonstrated in experimental studies in normal, splenectomized and hypersplenic animals without portal hypertension, where platelet counts correlated with spleen weight and total body platelet mass was similar in the three groups (21). Surprisingly, platelet survival time was also the same in all three groups, because platelet removal in splenectomized animals was largely accomplished by the liver.

Human cases were reported by Aster (15) and Penny et al (22), who recovered $62 \%$ to $89 \%$ of total body platelet mass after ex vivo perfusion of massively enlarged spleens in one patient with cirrhosis and one with extraportal hypertension, respectively.

The clinical data on relief of portal hypertension do not show such unequivocal results. Several studies report on the effect of portocaval shunts on hypersplenism in cirrhosis of the liver (for an incomplete list see Table 1).

After portocaval shunt operations for variceal bleeding, Rousselot et al (23) could not demonstrate a significant improvement in platelet counts, while Hutson et al (24) claimed that his group did. In fact, there was improvement in peripheral platelet count after shunt surgery in 11 of 13 thrombocytopenic patients, but many of them still remained thrombocytopenic. In addition, the analysis did not take into account that six patients with a normal platelet count before surgery became thrombocytopenic after shunt surgery. Overall, there was no significant difference between platelet counts before and after shunt surgery.

Almost all of these studies suffer from severe methodological problems. They are retrospective analyses of patients who underwent shunt surgery for bleeding varices at various time points after the bleeding episode. It is impossible to distinguish between spontaneous recovery of platelet count after a bleeding episode, which often times is quite dramatic, and the true effects of portal decompression on the incidence of 'hypersplenism'. None of these studies contain a control group of patients undergoing conservative or endoscopic treatment, and most of them only report on a very select segment of their patient population undergoing shunt surgery namely those with pronounced thrombocytopenia but relatively good liver function (allowing them to undergo shunt surgery). In essence, no conclusion can be drawn from these studies regarding the effect of portocaval anastomosis on peripheral platelet counts in patients with cirrhosis of the liver.

The exception is a study by Mutchnick et al (25), who reported on patients with portal hypertension and esophageal varices but without a prior bleeding episode. The patients were placed randomly in controlled trials of prophylactic shunt surgery. Portal pressure gradient, and incidence of splenomegaly and thrombocytopenia were similar in both groups. While the reversal of splenomegaly in the shunt group did not quite reach statistical significance (after an average follow-up of 5.5 years), the effects on thrombocytopenia were the same in both groups. No improvement of thrombocytopenia could be found in either group. If anything, the incidence of thrombocytopenia increased in both the control group and surgical shunt group during the five years of follow-up.

Several studies of thrombocytopenia post-transjugular intrahepatic portosystemic shunt (TIPS) have been published, but most of them report on use only after an acute bleeding episode or on selected patients with more severe thrombocytopenia, show only limited data, and suffer from the same shortcomings as the surgical shunt studies (26-29). A study of 44 unselected patients by the author showed no increase in platelet count, neither at 14 days nor at one year postTIPS implantation (30), a finding also observed by others (31). 
The correlation between spleen size and platelet count in patients with cirrhosis is also not firmly established. Jalan et al (28) showed that, in patients who underwent TIPS placement, there was an improvement in platelet count, but failed to show that there was a correlation between either portal pressure or spleen size and the recovery of platelet count. Data from the author (unpublished observations) on patients undergoing liver transplantation also do not indicate any correlation between spleen size and platelet count, while Mutchnick et al (25) in their study on portocaval anastomosis patients at least noted a trend.

Several groups have demonstrated the recovery of platelet counts in thrombocytopenic patients with cirrhosis of the liver after embolization of large parts of the spleen (32-34). In principle, this is another form of splenectomy and increases peripheral platelet count, most likely by prolonging platelet survival time. In animal studies of experimental splenectomy, platelet survival was unchanged in both splenectomized and control rats because the liver took over platelet removal from the spleen. This might not be the case in humans, however, especially when the liver is cirrhotic.

There are very few studies on peripheral platelet counts in noncirrhotic patients with extrahepatic or presinusoidal portal hypertension. The effects of extrahepatic portal hypertension on peripheral platelet counts have been studied in patients with portal venous thrombosis (35), while presinusoidal hypertension without severe hepatocellular damage can be found in patients with schistosomiasis (36). Platelet counts in patients with extrahepatic portal hypertension were between normal controls and patients with portal hypertension and liver disease (35), suggesting dual mechanisms for thrombocytopenia in liver disease: splenic sequestration of platelets due to portal hypertension and a further decrease in peripheral platelet count due to reduced hepatocellular function. This is also demonstrated by heterotopic liver transplantation (HLT), which relieves portal hypertension by the creation of a portocaval shunt and restores liver synthetic function by transplantation of a functioning liver graft. HLT resolves thrombocytopenia very effectively (37), contrary to the simple relief of portal hypertension without restoration of liver synthetic function. Therefore, portal hypertension seems to play some role in thrombocytopenia in liver disease, but adequate liver synthetic function is essential for the maintenance or restoration of a normal peripheral platelet count.

\section{BONE MARROW PRODUCTION OF PLATELETS IN CIRRHOSIS}

Indirect information about bone marrow production of thrombocytes is available from various turnover studies, but the methodology used in the studies was quite heterogeneous as are the results of these studies. Different radioligands $\left({ }^{51} \mathrm{Cr},{ }^{111} \mathrm{In}\right)$ used for labelling of platelets and different methodologies for calculating platelet turnover (38) make it difficult to compare these studies.

Very little direct information is available about the bone marrow of patients with cirrhosis of the liver. After using commonly available search machines and looking through citations in older literature extending beyond the 1960s, no systematic study on megakaryopoeisis and thrombocytopoiesis in patients with cirrhosis of the liver could be found, probably because quantification of megakaryopoiesis is methodologically cumbersome and biopsy of bone marrow is rarely justified by the moderate degree of cytopenia. One study by Harker and Finch (39) assessed thrombokinetics in 83 patients with thrombocytopenia, including one patient with cirrhosis of the liver, and found that thrombocyte production decreased to $70 \%$ of normal. Another study by the same author (40) showed a wide range of platelet production rates, platelet survival and peripheral platelet counts in a very heterogeneous population of patients with cirrhosis of the liver. In these patients, the peripheral platelet count was a direct manifestation of platelet production in the bone marrow. In a recent study using reticulated platelets in the peripheral blood as markers of thrombopoiesis, it could be demonstrated that thrombocytopenia in liver disease is caused by a low platelet production rate, just as in aplastic anemia and unlike thrombocytopenia with high platelet turnover in conditions such as idiopathic thrombocytopenic purpura (ITP) (41).

\section{THROMBOPOIETIN}

In 1994, TPO was discovered. TPO is almost exclusively expressed in the liver, with only minor amounts originating from the kidneys and other sources (42). What makes TPO so ideal for playing a key role in the etiology of thrombocytopenia in liver disease is the unique mechanism of regulating TPO serum levels. TPO serum levels depend on two major factors: TPO production in the liver; and the binding of TPO to its receptors, which are located on thrombocytes and megakaryocytes (43). TPO clearance from the circulation depends on peripheral platelet count. Even though megakaryocytes contain up to 10 times more receptors per cell than circulating platelets, the TPO receptors found on platelets still make up more than $95 \%$ of the TPO-removing receptors. TPO production by the liver is constant and is not regulated at the transcriptional level (44). One hepatocyte seems to produce the same amount of TPO at all times, and upregulation of TPO production does not occur. Therefore, the amount of TPO produced in the liver depends on the functional liver cell mass, providing the rationale to assume that TPO plays a role in thrombocytopenia in liver disease.

\section{EXPERIMENTAL EVIDENCE}

In 1975, Siemensma and colleagues (45) showed in an animal model that peripheral platelet count is somewhat related to functional liver mass. After a four-fifths hepatectomy, animals became thrombocytopenic within two days and their peripheral platelet counts recovered only by day 8 , when the liver had already regained $80 \%$ of its previous weight. In the same study, they showed that recovery from acute thrombocytopenia induced by treatment with antiplatelet serum took much longer in rats after a four-fifths he- 


\section{COPYRIGHT PULSUS GROUP INC, DO NOT,COPY}

TABLE 1

Portocaval anastomosis (PCA) and thrombocytopenia in cirrhosis of the liver

\begin{tabular}{|c|c|c|c|c|c|c|c|}
\hline Author (reference) & $\mathbf{n}$ & Study design & $\begin{array}{c}\text { Thrombocytopenia } \\
\text { preshunt }(\%)\end{array}$ & $\begin{array}{l}\text { Thrombocytopenia } \\
\text { postshunt (\%) }\end{array}$ & Improved (\%) & Worse (\%) & Comment \\
\hline Rousselot et al (23) & 104 & Retrospective & $15(14)$ & $10(10)$ & $5(5)$ & $5(5)$ & $\begin{array}{l}\text { Posthemorrhage, } \\
\text { elective shunt }\end{array}$ \\
\hline Hutson et al (24) & 66 & Retrospective & $13(20)$ & $11(17)$ & $11(17)$ & $6(9)$ & Posthemorrhage \\
\hline Ferrara et al (73) & 47 & Retrospective & $19(40)$ & $\begin{array}{l}\text { Data } \\
\text { incomplete }\end{array}$ & $\begin{array}{l}\text { Data } \\
\text { incomplete }\end{array}$ & $\begin{array}{c}\text { Data } \\
\text { incomplete }\end{array}$ & Posthemorrhage \\
\hline Mutchnik et al (25) & 93 & Prospective RCT & $5(5)$ & $13(14)$ & $4(4)$ & $12(13)$ & $\begin{array}{c}\text { Prophylactic shunt, } \\
\text { no prior } \\
\text { hemorrhage }\end{array}$ \\
\hline el-Khishen et al (74) & 33 & Retrospective & $33(100)$ & $22(66)$ & No data & No data & $\begin{array}{c}\text { Platelets }<50,000, \\
\text { posthemorrhage }\end{array}$ \\
\hline McAllister et al (75) & 74 & Retrospective & $34(46)$ & $10(14)$ & No data & No data & Posthemorrhage \\
\hline
\end{tabular}

RCT Randomized clinical trial

patectomy than in control animals, again linking peripheral platelet count to liver cell mass.

After the cloning of TPO and its receptor (c-mpl), it was demonstrated in knock-out animals that there was a clear dose-response relationship between either TPO or its receptor c-mpl and peripheral platelet counts. Homozygous TPO knock-out mice showed a greater than $80 \%$ reduction in peripheral platelet mass, while heterozygous animals had $60 \%$ of the peripheral platelet count of control animals (46). Likewise, c-mpl knock-out mice had a greater than $85 \%$ reduction of peripheral platelet count (47). In very elegant experiments, Qian et al (48) tried to determine the contribution of liver-derived TPO to megakaryopoiesis and thrombocytopoiesis in mice by transplanting livers from TPO knock-out mice into syngeneic wild-type mice. They showed that the liver contributes $60 \%$ of the TPO required for maintenance of normal platelet count in mice. In humans, this fraction will likely be higher because, as judged from mRNA expression in Northern blots, TPO in humans is mostly produced in the liver, and TPO production in the kidneys of mice exceeds that in humans markedly $(42,49)$.

\section{PATIENTS WITH CIRRHOSIS OF THE LIVER}

Several groups have published data on TPO serum or plasma levels in patients with cirrhosis of the liver and have come to opposing conclusions in the interpretation of their data. Overall, most groups have found unchanged, slightly elevated or reduced TPO levels in patients with various stages of liver cirrhosis compared with control patients (18-20,5057). All of the reported TPO levels in patients with cirrhosis of the liver were in the range of normal. Even though the authors have tried to come to different conclusions from their data, little insight can be gained without additional information about platelet production and turnover in these patients. The only mechanism for thrombocytopenia in liver disease that can be excluded from these data is predominant bone marrow failure due to liver disease-associated toxins with normal TPO production by the liver. This would require high TPO serum levels in thrombocytopenic patients, similar to patients undergoing chemotherapy for malignant disease, but high TPO levels are not observed in patients with liver disease.

The author and others have demonstrated that TPO serum levels are in the normal range in patients with advanced-stage liver disease and thrombocytopenia. TPO levels in the normal range with thrombocytopenia cannot be regarded as 'normal', because a compensatory increase in TPO serum levels would be expected $(41,50,57,58)$. Normal TPO levels with low peripheral platelet count can theoretically be observed in two clinical conditions: in high turnover states such as ITP, where bone marrow production of platelets is increased but newly formed platelets are rapidly destroyed, or through reduced TPO production by the liver, which usually does not occur. Controversy about the pathophysiology of thrombocytopenia in liver disease exists because in the past, a state of consumption coagulopathy has been postulated for patients with advanced-stage liver disease. Overt consumption coagulopathy can only be observed during episodes of active bleeding or in acute liver failure (59). Low-level consumption coagulopathy can sometimes also be observed in patients with stable liver disease. It seems to occur mainly during periods of endotoxemia and affects the plasmatic coagulation system but has not been shown to have any influence on peripheral platelet count (17). Overall, consumption coagulopathy, even at low levels, seems to be more the exception than the rule, even in advanced-stage liver disease (16).

Recently, a study published by Koike et al (41) was able to shed some light onto this issue. By comparing platelet production (measured as reticulated platelets) and TPO serum levels in thrombocytopenic patients with aplastic anemia, ITP and cirrhosis of the liver, they were able to show that TPO levels are increased and platelet production is decreased in patients with aplastic anemia. Patients with cirrhosis show normal TPO levels, which are too low considering the peripheral platelet count in these patients, while platelet production by the bone marrow is reduced. This is the first study showing that the gradual decline in liver function in cirrhosis, with a gradual decline in TPO production by the liver, results in a low platelet production 
rate by the bone marrow. This rules out a high turnover state with increased platelet destruction in patients with cirrhosis of the liver.

\section{PATIENTS UNDERGOING LIVER TRANSPLANTATION}

Because the serum levels of TPO in patients with cirrhosis do not explain the mechanism leading to thrombocytopenia in cirrhosis of the liver, the next area of study was liver transplantation. It had been shown that liver transplantation, either orthotopic liver transplantation (OLT) (1) or HLT (37), is associated with a rapid correction of thrombocytopenia if present before liver transplantation. It was hypothesized that TPO serum levels and a declining peripheral platelet count during the progression of chronic liver disease always remained in an equilibrium, characterized by reduced platelet production and consequently less removal of TPO from the circulation by binding. Liver transplantation in patients with advanced-stage liver disease and thrombocytopenia would restore normal TPO production immediately with a persistently low platelet count. This would lead to a sharp rise in TPO serum levels within the first two days of liver transplantation. Increased TPO serum levels post-OLT would only decline together with a marked increase in peripheral platelet count.

Indeed, it could be shown that TPO levels start to increase at day 1 post-transplantation and that the increase in TPO levels paralleled the course of recovery of liver synthetic function as shown by the increase in clotting factors $(18,58)$. The increase in TPO serum levels is dependent on the pre-OLT platelet count, because only patients with thrombocytopenia before OLT show an increase in TPO serum levels, while patients with normal platelet count before OLT do not (50). The gradual increase in TPO serum levels and clotting factors within the initial two to three days after OLT did not come as a surprise, because immediately after reperfusion of the graft, coagulation and hyperfibrinolysis activation are well documented $(60,61)$. This hypercoagulative state causes consumption of clotting factors and thrombocytes, but subsides after the first day after surgery. Together with thrombocyte consumption on day 1 , the clearance of TPO from the circulation is accelerated. Nevertheless, TPO serum levels are significantly elevated already on day 1 postOLT and peak between days 2 to 5 post-OLT when platelet counts are still low without any ongoing coagulation activation or platelet consumption (58). Around day 6 post-OLT, the peripheral platelet count starts to increase, which is in good accordance with the time lag observed between the administration of recombinant human TPO and the increase in peripheral platelet count in humans (62). By day 14, most patients have peripheral platelet counts in the normal range and all patients with an uncomplicated postoperative course have significantly higher platelet counts than before OLT (18). This increase in peripheral platelet count does not simply reflect relief of portal hypertension, which is a consequence of OLT, but is related to liver graft function $(61,63,64)$.

This relation to liver graft function is supported by the fact that the increase in platelet count post-OLT is selective for thrombocyte counts, as expected for the effect exerted by a lineage-specific growth factor like TPO. Neither hemoglobin nor white blood cells show any significant change within the first 14 days post-OLT, as one would expect if relief of 'hypersplenism' was the mechanism for the increase in peripheral platelet count post-OLT.

\section{CONCLUSIONS}

The etiology of thrombocytopenia in liver disease cannot be attributed to a single cause with certainty. Even after decades of holding 'hypersplenism' as the major theory to explain low peripheral platelet counts in patients with liver cirrhosis, clarifying studies showing the correlation between portal pressure, spleen size, bone marrow production of platelets, platelet survival time and peripheral platelet count are lacking. The evidence to date in the etiology of thrombocytopenia in liver disease favours a combined role of portal hypertension and splenic sequestration on one hand, and of decreased TPO production by the diseased liver on the other hand. This combination is suggested because decreased TPO production on its own cannot explain thrombocytopenia in liver disease in all patients convincingly.

The ultimate proof of the role of portal hypertension versus the lack of TPO production in thrombocytopenia would be the correction of thrombocytopenia by the administration of recombinant human TPO (rH-TPO) (Genentech Inc, USA) or its synthetic C-terminally truncated and pegylated analogue, recombinant human megakaryocyte growth and development factor (rH-MGDF) (Amgen Inc, USA). Unfortunately, two phase 1 studies of patients with cirrhosis and thrombocytopenia were stopped before they were started due to problems with the recombinant TPO analogue rH-MGDF. The analogue caused production of neutralizing antibodies that cross-reacted with the endogenous molecule in healthy individuals after repeat administration in platelet donors (65). Problems with neutralizing antibodies have not been described in several hundred oncological patients receiving rH-MGDF $(66,67)$ or the full-length recombinant molecule rH-TPO (62), maybe because these patients were immunosuppressed to a certain degree. Otherwise, the safety profile of the recombinant TPOs are very favourable, with virtually no side effects except for very high peripheral platelet counts (greater than $1,000,000 / \mu \mathrm{L}$ ) in some patients, which have not caused any thrombotic complications so far. In particular, platelet aggregation and activation are not induced through rH-TPO (68). After careful assessment of the problem with neutralizing antibodies, clinical studies involving the various states of thrombocytopenia, outside the oncological setting, should resume. Patients with liver disease would be an ideal target population for these studies, once phase 1 studies in patients with stable cirrhosis and thrombocytopenia have shown safety and efficacy. Possible indications to study the efficacy of rH-TPO would be thrombocytopenic patients undergoing invasive diagnostic procedures or surgery, patients after variceal hemorrhage, patients undergoing OLT to decrease the rate of postoperative bleed- 
ing complications or patients awaiting OLT to decrease the intraoperative need for blood products. Maybe the most interesting patient group to study would be patients undergoing interferon-alpha treatment for chronic hepatitis C. Thrombocytopenia is a frequent and dose-dependent side effect of interferon treatment for chronic hepatitis $\mathrm{C}$ and is already the reason for a dose reduction or termination of treatment in a considerable number of patients. As shown recently, not only bone marrow production of platelets, but also TPO production in the liver, is hampered by interferon therapy (20). There is increasing evidence that higher doses and prolonged treatment intervals might improve virological responses (69), and that the treatment of patients with hepatitis $\mathrm{C}$ cirrhosis (previously not considered a group to benefit from interferon therapy) might improve their survival $(70,71)$ and reduce the incidence of hepatocellular carcinoma $(71,72)$. Therefore, a potent yet well-tolerated thrombopoietic agent will be in high demand, an agent such as recombinant human TPOs. It is hoped that it will be available to treat thrombocytopenia in liver disease in the future.

\section{REFERENCES}

1. Yanaga K, Tzakis AG, Shimada M, et al. Reversal of hypersplenism following orthotopic liver transplantation. Ann Surg 1989;210:180-3.

2. Realdi G, Fattovich G, Hadziyannis S, et al. Survival and prognostic factors in 366 patients with compensated cirrhosis type B: a multicenter study. The Investigators of the European Concerted Action on Viral Hepatitis (EUROHEP). J Hepatol 1994;21:656-66.

3. Cabrera J, Maynar M, Granados R, et al. Transjugular intrahepatic portosystemic shunt versus sclerotherapy in the elective treatment of variceal hemorrhage. Gastroenterology 1996;110:832-9.

4. Goulis J, Armonis A, Patch D, Sabin C, Greenslade L, Burroughs AK. Bacterial infection is independently associated with failure to control bleeding in cirrhotic patients with gastrointestinal hemorrhage. Hepatology 1998;27:1207-12.

5. Basili S, Ferro D, Leo R, et al. Bleeding time does not predict gastrointestinal bleeding in patients with cirrhosis. The CALC Group. Coagulation Abnormalities in Liver Cirrhosis. J Hepatol 1996;24:574-80.

6. Clavien PA, Camargo CA Jr, Croxford R, Langer B, Levy GA, Greig PD. Definition and classification of negative outcomes in solid organ transplantation. Application in liver transplantation. Ann Surg 1994;220:109-20.

7. McVay PA, Toy PT. Lack of increased bleeding after liver biopsy in patients with mild hemostatic abnormalities. Am J Clin Pathol 1990;94:747-53.

8. Violi F, Ferro D, Basili S, et al. Hyperfibrinolysis increases the risk of gastrointestinal hemorrhage in patients with advanced cirrhosis. Hepatology 1992;15:672-6.

9. López Morante AJ, Sáez-Royuela F, Casanova Valero F, Yuguero del Moral L, Martín Lorente JL, Ojeda Giménez C. Immune thrombocytopenia after alpha-interferon therapy in a patient with chronic hepatitis C. Am J Gastroenterol 1992;87:809-10.

10. Feistauer SM, Penner E, Mayr WR, Panzer S. Target platelet antigens of autoantibodies in patients with primary biliary cirrhosis. Hepatology 1997;25:1343-5.

11. Hoofnagle JH. Thrombocytopenia during interferon alfa therapy. JAMA 1991;266:849.

12. Young NS. Flaviviruses and bone marrow failure. JAMA 1990;263:3065-8.

13. Hoofnagle JH, di Bisceglie AM. The treatment of chronic viral hepatitis. N Engl J Med 1997;336:347-56.

14. Dourakis SP, Deutsch M, Hadziyannis SJ. Immune thrombocytopenia and alpha-interferon therapy. J Hepatol 1996;25:972-5.

15. Aster RH. Pooling of platelets in the spleen: role in the pathogenesis of "hypersplenic" thrombocytopenia. J Clin Invest 1966;45:645-57.
16. Carr JM. Disseminated intravascular coagulation in cirrhosis. Hepatology 1989;10:103-10.

17. Violi F, Ferro D, Basili S, et al. Association between low-grade disseminated intravascular coagulation and endotoxemia in patients with liver cirrhosis. Gastroenterology 1995;109:531-9.

18. Peck-Radosavljevic M, Zacherl J, Meng YG, et al. Is inadequate thrombopoietin production a major cause of thrombocytopenia in cirrhosis of the liver? J Hepatol 1997;27:127-31.

19. Martin TG III, Somberg KA, Meng YG, et al. Thrombopoietin levels in patients with cirrhosis before and after orthotopic liver transplantation. Ann Intern Med 1997;127:285-8.

20. Peck-Radosavljevic M, Wichlas M, Pidlich J, et al. Blunted thrombopoietin response to interferon alfa-induced thrombocytopenia during treatment for hepatitis C. Hepatology 1998;28:1424-9.

21. De Gabriele G, Penington DG. Regulation of platelet production: "hypersplenism" in the experimental animal. Br J Haematol 1967;13:384-93.

22. Penny R, Rozenberg MC, Firkin BG. The splenic platelet pool. Blood 1966;27:1-16.

23. Rousselot LM, Panke WF, Bono RF, Moreno AH. Experiences with portacaval anastomosis. Analysis of 104 elective end-to-side shunts for the prevention of recurrent hemorrhage from esophagogastric varices (1952 through 1961). Am J Med 1963;34:297-307.

24. Hutson DG, Zeppa R, Levi JU, Schiff ER, Livingstone AS, Fink P. The effect of the distal splenorenal shunt on hypersplenism. Ann Surg 1977;185:605-12.

25. Mutchnick MG, Lerner E, Conn HO. Effect of portacaval anastomosis on hypersplenism. Dig Dis Sci 1980;25:929-38.

26. Lawrence SP, Lezotte DC, Durham JD, Kumpe DA, Everson GT, Bilir BM. Course of thrombocytopenia of chronic liver disease after transjugular intrahepatic portosystemic shunts (TIPS). A retrospective analysis. Dig Dis Sci 1995;40:1575-80.

27. Alvarez OA, Lopera GA, Patel V, Encarnacion CE, Palmaz JC, Lee M. Improvement of thrombocytopenia due to hypersplenism after transjugular intrahepatic portosystemic shunt placement in cirrhotic patients. Am J Gastroenterol 1996;91:134-7.

28. Jalan R, Redhead DN, Allan PL, Hayes PC. Prospective evaluation of haematological alterations following the transjugular intrahepatic portosystemic stent-shunt (TIPSS). Eur J Gastroenterol Hepatol 1996;8:381-5.

29. Pursnani KG, Sillin LF, Kaplan DS. Effect of transjugular intrahepatic portosystemic shunt on secondary hypersplenism. Am J Surg 1997;173:169-73.

30. Wichlas M, Pidlich J, Zacherl J, et al. Continuing thrombocytopenia after TIPS-implantation cannot be attributed to thrombocyte consumption. Hepatology 1997;26:A2002. (Abst)

31. Jabbour N, Zajko A, Orons P, Irish W, Fung JJ, Selby RR. Does transjugular intrahepatic portosystemic shunt (TIPS) resolve thrombocytopenia associated with cirrhosis? Dig Dis Sci 1998;43:2459-62.

32. Kumpe DA, Rumack CM, Pretorius DH, Stoecker TJ, Stellin GP. Partial splenic embolization in children with hypersplenism. Radiology 1985;155:357-62.

33. Sangro B, Bilbao I, Herrero I, et al. Partial splenic embolization for the treatment of hypersplenism in cirrhosis. Hepatology 1993;18:309-14.

34. Noguchi H, Hirai K, Aoki Y, Sakata K, Tanikawa K. Changes in platelet kinetics after a partial splenic arterial embolization in cirrhotic patients with hypersplenism. Hepatology 1995;22:1682-8.

35. Robson SC, Kahn D, Kruskal J, Bird AR, Kirsch RE. Disordered hemostasis in extrahepatic portal hypertension. Hepatology 1993;18:853-7.

36. Raia S, Mies S, Alfieri F Jr. Portal hypertension in mansonic schistosomiasis. World J Surg 1991;15:176-87.

37. Rinkes IH, Van der Hoop AG, Hesselink EJ, et al. Does auxiliary heterotopic liver transplantation reverse hypersplenism and portal hypertension? Gastroenterology 1991;100:1126-8.

38. Amuasi JH, Ferri P, Grossi A, Vannucchi L, Vannucchi AM, Ferrini PR. Quantitative platelet imaging and comparison of four mathematical models for the evaluation of platelet mean life span in patients with chronic immune thrombocytopenia. Haematologica 1991;76:104-8.

39. Harker LA, Finch CA. Thrombokinetics in man. J Clin Invest 1969;48:963-74.

40. Stein SF, Harker LA. Kinetic and functional studies of platelets, fibrinogen, and plasminogen in patients with hepatic cirrhosis. J Lab Clin Med 1982;99:217-30. 
41. Koike Y, Yoneyama A, Shirai J, et al. Evaluation of thrombopoiesis in thrombocytopenic disorders by simultaneous measurement of reticulated platelets of whole blood and serum thrombopoietin concentrations. Thromb Haemost 1998;79:1106-10.

42. de Sauvage FJ, Hass PE, Spencer SD, et al. Stimulation of megakaryocytopoiesis and thrombopoiesis by the c-Mpl ligand. Nature 1994;369:533-8.

43. Fielder PJ, Gurney AL, Stefanich E, et al. Regulation of thrombopoietin levels by c-mpl-mediated binding to platelets. Blood 1996;87:2154-61.

44. Stoffel R, Wiestner A, Skoda RC. Thrombopoietin in thrombocytopenic mice: evidence against regulation at the mRNA level and for a direct regulatory role of platelets. Blood 1996;87:567-73.

45. Siemensma NP, Bathal PS, Penington DG. The effect of massive liver resection on platelet kinetics in the rat. J Lab Clin Med 1975;86:817-33.

46. de Sauvage FJ, Carver-Moore K, Luoh SM, et al. Physiological regulation of early and late stages of megakaryocytopoiesis by thrombopoietin. J Exp Med 1996;183:651-6.

47. Gurney AL, Carver-Moore K, de Sauvage FJ, Moore MW. Thrombocytopenia in c-mpl-deficient mice. Science 1994;265:1445-7.

48. Qian S, Fu F, Li W, Chen Q, de Sauvage FJ. Primary role of the liver in thrombopoietin production shown by tissue-specific knockout. Blood 1998;92:2189-91. (Lett)

49. Lok S, Kaushansky K, Holly RD, et al. Cloning and expression of murine thrombopoietin cDNA and stimulation of platelet production in vivo. Nature 1994;369:565-8.

50. Goulis J, Chau TN, Jordan S, Mehta AB, Rolles K, Burroughs AK. Thrombopoietin (TPO) in cirrhosis and after orthotopic liver transplantation (OLT). J Hepatol 1998;28(Suppl 1):64. (Abst)

51. Harada K, Shiota G, Okubo M, Okano H, Kawasaki H. Expression of thrombopoietin in chronic liver diseases. Hepatology 1997;26:520A. (Abst)

52. Kato N, Shiratori Y, Ono-Nita SK, et al. Comparison of serum thrombopoietin levels between patients with cirrhosis and idiopathic portal hypertension. Hepatology 1997;26:538A. (Abst)

53. Sezai S, Kamisaka K, Ikegami F, et al. Regulation of hepatic thrombopoietin production by portal hemodynamics in liver cirrhosis. Am J Gastroenterol 1998;93:80-2.

54. Shimodaira S, Ishida F, Ichikawa N, et al. Serum thrombopoietin (c-mpl ligand) levels in patients with liver cirrhosis. Thromb Haemost 1996;76:545-8.

55. Koike Y, Yoneyama A, Shirai J, et al. Evaluation of thrombopoiesis in thrombocytopenic disorders by simultaneous measurement of reticulated platelets of whole blood and serum thrombopoietin concentrations. Thromb Haemost 1998;79:1106-10.

56. Wang YJ, Chang FY, Lee SD. Thrombopoietin levels in patients with liver cirrhosis. Hepatology 1998;28:196A. (Abst)

57. Ishikawa T, Ichida T, Matsuda Y, et al. Reduced expression of thrombopoietin is involved in thrombocytopenia in human and rat liver cirrhosis. J Gastroenterol Hepatol 1998;13:907-13.

58. Peck-Radosavljevic M, Wichlas M, Zacherl J, et al. Thrombopoietin-deficiency, DIC, thrombocyte consumption, and thrombocytopenia in cirrhosis. J Hepatol 1998; 28(Suppl 1):77. (Abst)
59. Rake MO, Flute PT, Pannell G, Williams R. Intravascular coagulation in acute hepatic necrosis. Lancet 1970;i:533-7.

60. Stahl RL, Duncan A, Hooks MA, Henderson JM, Millikan WJ, Warren WD. A hypercoagulable state follows orthotopic liver transplantation. Hepatology 1990;12:553-8.

61. Porte RJ, Blauw E, Knot EA, et al. Role of the donor liver in the origin of platelet disorders and hyperfibrinolysis in liver transplantation. J Hepatol 1994;21:592-600.

62. Vadhan-Raj S, Murray LJ, Bueso-Ramos C, et al. Stimulation of megakaryocyte and platelet production by a single dose of recombinant human thrombopoietin in patients with cancer. Ann Intern Med 1997;126:673-81.

63. Chatzipetrou MA, Weppler D, Tsaroucha A, et al. Thrombocytopenia following liver transplantation. Gastroenterology 1998;114:A1224. (Abst)

64. Sindram D, Porte RJ, Clavien PA. Persistent thrombocytopenia is related to initial graft injury in human liver transplantation. J Hepatol 1998;28(Suppl):355A.

65. Martin TG, Shuman MA. Interferon-induced thrombocytopenia: is it time for thrombopoietin? Hepatology 1998;28:1430-2.

66. Basser RL, Rasko JE, Clarke K, et al. Thrombopoietic effects of pegylated recombinant human megakaryocyte growth and development factor (PEG-rHuMGDF) in patients with advanced cancer. Lancet 1996;348:1279-81.

67. Basser RL, Rasko JE, Clarke K, et al. Randomized, blinded, placebo-controlled phase I trial of pegylated recombinant human megakaryocyte growth and development factor with filgrastim after dose-intensive chemotherapy in patients with advanced cancer. Blood 1997;89:3118-28.

68. Begley CG. Clinical studies with megakaryocyte growth and development factor (Mpl-ligand). Thromb Haemost 1997;78:42-6.

69. Poynard T, Opolon P. Hepatitis C: somber views of natural history and optimistic views of interferon treatment? Hepatology 1998;27:1443-4.

70. Niederau C, Lange S, Heintges T, et al. Prognosis of chronic hepatitis C: results of a large, prospective cohort study. Hepatology 1998;28:1687-95.

71. Serfaty L, Aumaitre H, Chazouilleres O, et al. Determinants of outcome of compensated hepatitis $\mathrm{C}$ virus-related cirrhosis. Hepatology 1998;27:1435-40.

72. Nishiguchi S, Kuroki T, Nakatani S, et al. Randomised trial of effects of interferon-alpha on incidence of hepatocellular carcinoma in chronic active hepatitis $\mathrm{C}$ with cirrhosis. Lancet 1995;346:1051-5.

73. Ferrara J, Ellison EC, Martin EW Jr, Cooperman M. Correction of hypersplenism following distal splenorenal shunt. Surgery 1979;86:570-3.

74. el-Khishen MA, Henderson JM, Millikan WJ Jr, Kutner MH, Warren WD. Splenectomy is contraindicated for thrombocytopenia secondary to portal hypertension. Surg Gynecol Obstet 1985;160:233-8.

75. McAllister E, Goode S, Cordista AG, Rosemurgy A. Partial portal decompression alleviates thrombocytopenia of portal hypertension. Am Surg 1995;61:129-31. 


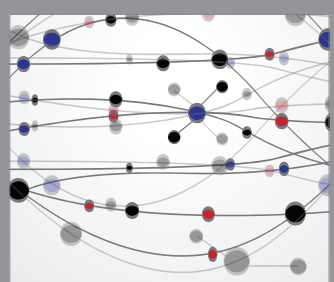

The Scientific World Journal
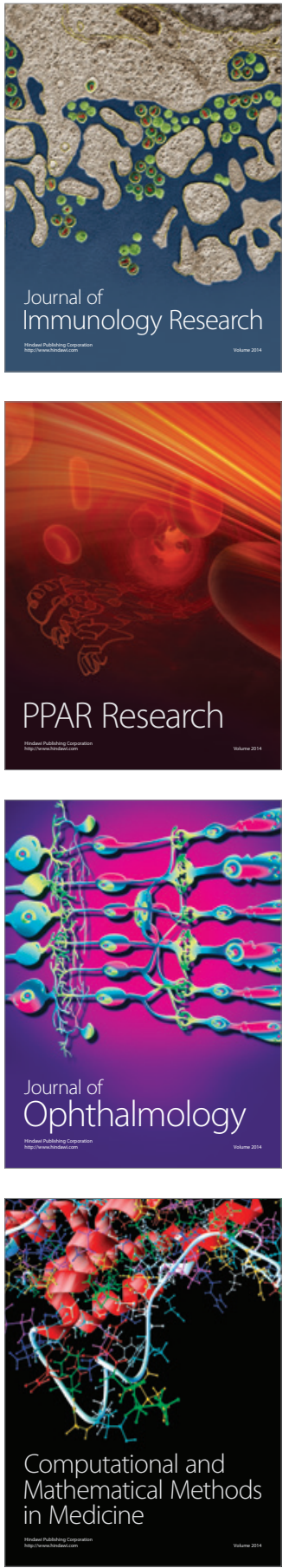

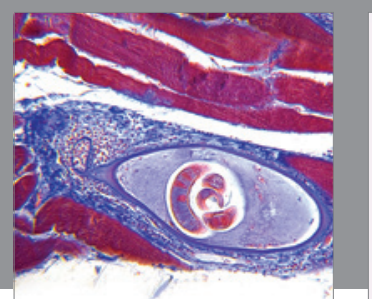

Gastroenterology Research and Practice

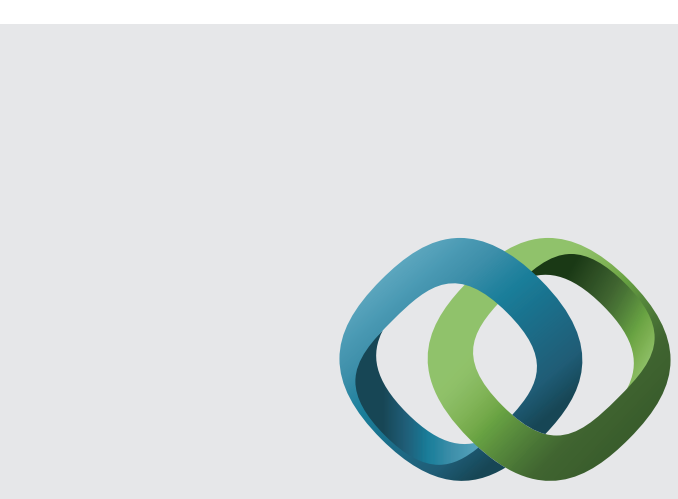

\section{Hindawi}

Submit your manuscripts at

http://www.hindawi.com
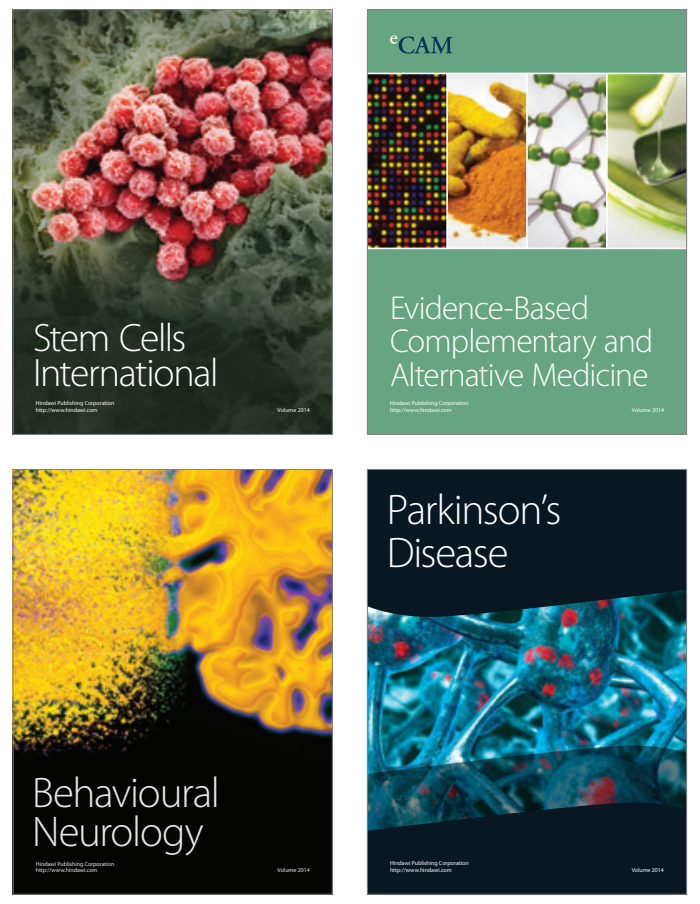
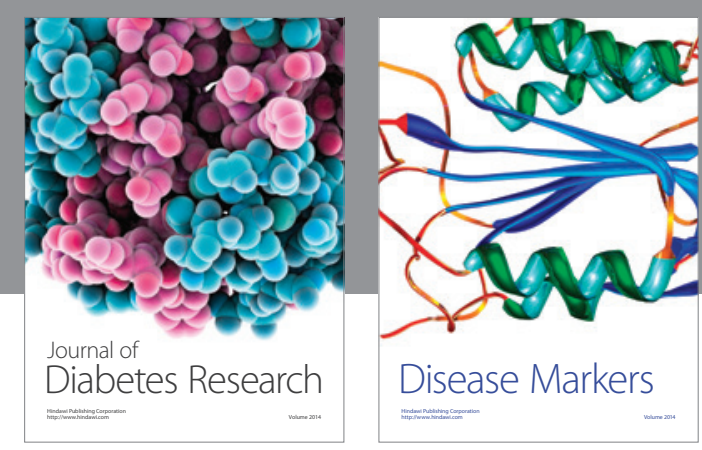

Disease Markers
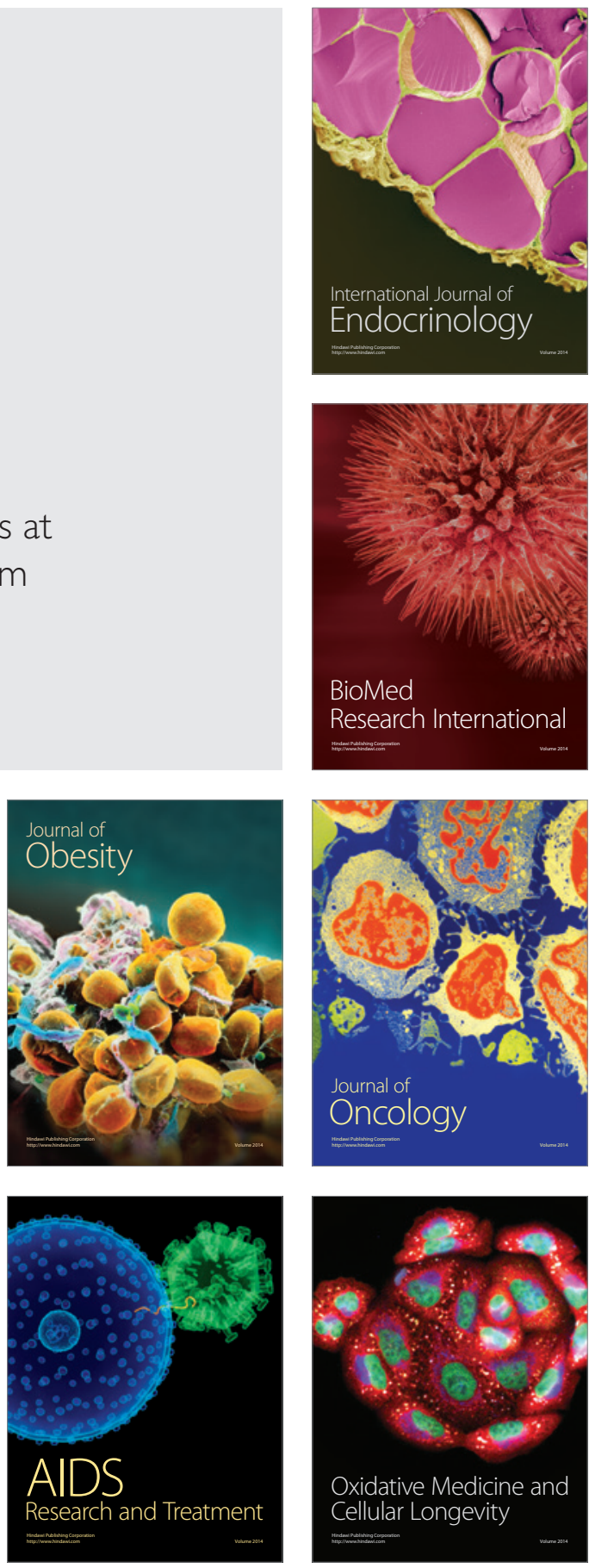